\title{
DAMAGE ASSESSMENT AND MONITORING OF CULTURAL HERITAGE PLACES IN A DISASTER AND POST-DISASTER EVENT - A CASE STUDY OF SYRIA
}

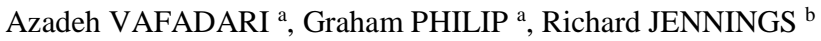 \\ ${ }^{a}$ Durham University, Dept. of Archaeology, Science Site, Durham DH1 3LE, U.K. - \\ (azadeh.vafadari, graham.philip)@durham.ac.uk \\ ${ }^{\mathrm{b}}$ Liverpool John Moores University, School of Natural Sciences and Psychology, Liverpool L3 3AF, U.K. - \\ r.p.jennings@ljmu.ac.uk
}

KEY WORDS: Emergency Recording, Heritage Database and Inventory, Damage and Condition Assessment, Risk Preparedness, Syria, Cultural Heritage and Disaster

\begin{abstract}
:
In recent decades, and in response to an increased focus on disastrous events ranging from armed conflict to natural events that impact cultural heritage, there is a need for methodologies and approaches to better manage the effects of disaster on cultural heritage. This paper presents the approaches used in the development of a Historic Environment Record (HER) for Syria. It describes the requirements and methodologies used for systematic emergency recording and assessment of cultural heritage. It also presents the type of information needed to record in the aftermath of disaster to assess the scale of damage and destruction. Started as a project at Durham University, the database is now being developed as part of the EAMENA (Endangered Archaeology in the Middle East and North Africa) project. The core dataset incorporates information and data from archaeological surveys undertaken in Syria by research projects in recent decades and began life as a development of the Shirin initiative ${ }^{1}$.

The focus of this project is to provide a tool not only for the recording and inventory of sites and monuments, but also to record damage and threats, their causes, and assess their magnitude. It will also record and measure the significance in order to be able to prioritize emergency and preservation responses. The database aims to set procedures for carrying out systematic rapid condition assessment (to record damage) and risk assessment (to record threat and level of risk) of heritage places, on the basis of both on the ground and remote assessment. Given the large number of heritage properties damaged by conflict, the implementation of rapid assessment methods to quickly identify and record level of damage and condition is essential, as it will provide the evidence to support effective prioritization of efforts and resources, and decisions on the appropriate levels of intervention and methods of treatment. The predefined data entry categories, use of a data standard, and systematic methods of assessment will ensure that different users choose from the same prefixed data entry and measurement inputs in order to allow for consistent and comparable assessments across different sites and regions. Given the general lack of appropriate emergency response and assessment databases, this system could also be applied in other locations facing similar threats and damage from conflict or natural disasters.
\end{abstract}

\section{INTRODUCTION}

Over the past decades cultural heritage in the Middle East and North Africa has been at risk of irreparable damage through conflict and neglect. In Syria since 2011 thousands of heritage places have suffered significant damage from conflict, looting, and the cessation of official monitoring and development controls. In preparing for the post-conflict reconstruction and rehabilitation stage in Syria, access to relevant information is essential. To work effectively the authorities must have access to a dataset which will inform them on the number, location, type, period, nature, and importance (in multiple senses) of heritage places. By knowing the severity of damage at heritage places, limited resources could be directed to where they are most needed. Implementation of the type of database system that give access to such information with a methodology embedded in it to provide a systematic way to record and assess condition as well as to identify priorities will play a crucial role in safeguarding Syria's cultural heritage.
With this in mind, a Historic Environment Record (HER) ${ }^{2}$ for Syria started to be developed at Durham University. Following the receipt of a British Council Cultural Protection Fund grant in December 2016, the project and the Syria HER have now become part of the broader EAMENA project. The capabilities developed for Syria HER are now being adapted and developed for the wider EAMENA database.

While the current situation in Syria limits on-the ground recording, assessment, and intervention, the database will enable advanced planning to take place until such a time when it is possible to work systematically on the ground in Syria. This will be principally through providing a platform for archaeologists and researchers to integrate their existing datasets of surveyed records into a single database platform. The initial dataset for Syria currently has around 15000 records mainly coming from years of regional surveys and large-scale settlement analysis projects in Syria by the Durham University Fragile Crescent Project and the Lyon University Paleosyr project. The database also provides a place to consolidate information on condition

\footnotetext{
${ }^{1}$ Syrian Heritage in Danger: an International Research Initiative and Network (http://shirin-international.org/)

${ }^{2}$ Historic Environment Records (HERs) in England are records of archaeological and historical sites, monuments, buildings, finds, and landscapes usually in the form of a database attached to a GIS (Geographic Information System). The same term is used to describe this project's database.
} 
status evaluations being conducted remotely (by different institutions) using satellite imagery and media reports.

This paper presents the approaches and methods used in the development of such a database.

\section{A HISTORIC ENVIRONMENT RECORD FOR SYRIA}

\subsection{Role of Inventory and Documentation Systems in Case of a Disaster Event}

In general, documentation and inventory is a foundation of heritage management. Inventories hold collections of documents and records in order to inform heritage professionals of what needs to be protected, where it is and why its protection is important. Well-regarded heritage inventory systems, containing searchable information on the location, characteristics, and condition of heritage places, allow users to analyse and manage heritage data. A good inventory not only improves the understanding of cultural heritage places, it is also essential for heritage interpretation, protection, preservation and management (ICOMOS, 1996; Council of Europe, 2009).

In the aftermath of disaster, an inventory and monitoring system is vital for heritage decision making and planning, namely to evaluate the condition of heritage, to help guide what should be protected on the ground (in the case of armed conflict), and to help guide new developments. Such systems also enable the comparison of heritage places (based on assessment of value, condition, etc.) to assist decision makers and heritage professionals to identify priorities and allocate limited resources. Potential uses of an inventory and management system in the aftermath of disaster could include the following:

- Tools for identifying and understanding of heritage places

- records containing information about location, characteristics, and condition of heritage places, and that facilitate identification and analysis of the heritage data

- Tools for protection, conservation and planning

- Provides a standardized approach to assess damage and threats to sites and monuments

- Permits prioritization of emergency and conservation responses based on available information about the sites, their condition, and their significance and values

- Tools for decision making and planning

- For decision makers (governmental authorities) and international donors, provides a tool to prioritize intervention activities and emergency actions and to mobilize and prioritize available funds

- During the rebuilding and reconstruction stage, helps to guide new developments

\subsection{Information Management}

From the beginning of the project it was a logical choice to build on an existing system that is designed specifically for heritage

\footnotetext{
${ }^{3}$ Arches has been developed by the Getty Conservation Institute (GCI) and World Monuments Fund (WMF) for the inventory, monitoring,
}

management, is standards-compliant and is easy to use, rather than to develop a database from scratch. Arches ${ }^{3}$, an inventory and management system purpose-built for handling information on immovable cultural heritage, was selected for this purpose. The software is open source (i.e. freely available), can be independently deployed, and can be customized, updated, and extended with new features by an international community of heritage professionals and IT specialists (GCI and WMF, 2016). More importantly Arches adopted international standards for heritage inventory including a documentation known as the International Committee for Documentation - Conceptual Reference Model (CIDOC - CRM) which is designed to provide a consistent semantic framework of heritage terminologies (ICOM CIDOC, 2015).

In addition, Arches is being used by other archaeology and heritage projects and organizations including EAMENA. The EAMENA project has customized the Arches database for use in the Middle East and North Africa regions. It has developed a methodology for the identification, recording, monitoring, and analysis of heritage places in the MENA region. Threats and damage to sites are recorded and monitored using satellite imagery and aerial data (Bewley et al., 2016). Now that the Syria HER project is part of the broader EAMENA project, the new capabilities developed as part of the Syria project to enable on the ground emergency recording, assessment and prioritization are being added to the EAMENA database in order to be applied at a wider scale in other countries of the MENA region facing similar challenges.

\subsection{Identification of Gaps and Main Functionalities}

While the initial approach of EAMENA - the remote assessment of sites and monuments- has the advantage of allowing for monitoring of cultural heritage properties from afar, its main limitation is the reduced level of certainty and accuracy in the assessment. It is therefore essential to have tools and methods in place for on-the-ground condition assessment for use as and when opportunities arise. In the Syrian context, and in general in a post disaster context, having set methodologies for data collection and systematic approaches of recording and assessment is an essential step in meeting post-war (postdisaster) challenges.

Furthermore in identifying gaps it was essential to note that archaeological research projects have different goals therefore use different recording methodologies which usually pay little attention to heritage management needs and priorities. In the Syrian context, given the threats and damage to archaeological sites, museum collections, libraries and archives, it is essential to develop heritage conservation and preservation strategies for preserving heritage as much as possible.

With this in mind, the main required functionalities of the Syria HER were developed. This system will be designed to:

- be used mainly as a Cultural Resource Management (CRM) tool and only secondarily as a research tool

- be used as a tool in an emergency and disaster contexts

- allow recording of on-the-ground assessment (in addition to remote assessment)

- embed within it methodology and procedures for emergency and rapid condition assessment

and management of heritage resources. It can be accessed at http://archesproject.org/ . 
- to record and locate damage and threats, their causes, severity and extent

- to assess level of damage and risk

- allow for rating/prioritizing sites and monuments based on the level of damage and significance

- provide a list of possible intervention, preservation and mitigation activities and needs that could be implemented when possible

- $\quad$ record sufficient information to be able to prioritize required conservation/reconstruction activities based on level of emergency and value

- (If possible) identify and apply a weighting system to each category of assessment to produce scores for damage, risk, and value

\section{DATA COLLECTION AND ASSESSMENT METHODOLOGY}

\subsection{Overview}

A standard method and format of collecting data is required in order to effectively identify, assess, compare, and analyse condition. Condition assessment identifies damage and threats in order to estimate the physical condition of a heritage place. In light of information on the physical condition, decision makers can determine the best way to preserve the values and integrity of heritage places and develop strategies to respond to any changes of the condition and damage that have been detected. A condition assessment could be implemented as part of the regular inspection of heritage places (e.g., twice a year, yearly, every 2 years, etc.). Gradual decay is one of the main causes of destruction. The detection of such damage, if monitored and treated as soon as it appears, can prevent irreversible destruction. A condition assessment can/should also be conducted after a natural and/or human impact event as part of emergency inspection. Examples may include after war or conflict, an earthquake, an even more routine or foreseeable events such as after a rainy season, or construction works near a heritage place. In the case of sudden destruction and post disaster interventions (both anthropogenic and natural), carrying out an emergency survey/assessment will allow the experts and decision makers to identify and understand the damage and threats (i.e. what more might happen as a result of this initial destruction and damage), and to identify and record damaged and under-threat heritage places. This emergency assessment usually needs to take place as soon as access is possible and the heritage place has been declared cleared by the authorities. As a result of this initial assessment, the immediate responses to secure and stabilize the heritage will be prioritized and implemented.

A rapid condition assessment followed by an emergency assessment will allow more detailed recording and assessment of individual damaged areas in order to identify and rank the intervention activities to be based on needs and importance, and to prepare a bespoke recovery and rehabilitation plan. Once the heritage places in need are identified, available funding and resources can then be allocated where emergency actions and interventions are most needed.

As the database allows recording these different type of assessments, in the updated version of EAMENA, one of the first things a user will do (after identifying the assessor and recording the date of assessment) is to record the type of activity/assessment: i.e. whether it is an emergency or rapid assessment, field or desk assessment, etc.

The following subsection provides a brief overview of the types of information required to be recorded for carrying out the emergency and rapid assessment.

\subsection{Elements of Emergency and Disaster Assessment}

In emergency assessment, such as the case in Syria, a standardized approach in identifying, recording and assessing damage and threats will allow heritage professionals to compare data and make informed decisions. Therefore, a standard format and set/type of information (i.e. data fields) for data collection must be developed, defined and implemented. Different people with different backgrounds have different ways to record and describe damage and threats to heritage sites and monuments. If different recording methods of assessment are used, it is more likely that the scale, standards and the quantity of information in each will be different, and perhaps incompatible. Analysing and comparing these different types of data becomes complicated and inhibiting its effective use in making management and conservation decisions.

A significant amount of research has already been carried out in the field of damage and risk assessment for cultural heritage (Waller, 2003; Walton, 2003; FISH, 2004; Council of Europe 2005, 2009, 2012; GCI and WMF, 2010; NCPTT, 2011; Vafadari, 2015). There has also been a recent surge of new projects reacting to the disaster caused by ongoing conflict in the Middle East. We build on this research and employ the most appropriate and suitable practices to identify the required elements. Particular attention has been paid to the Disaster Risk Management (DRM) cycle for cultural heritage, to ensure that the components of assessing risk and identifying mitigation strategies and responses in pre-disaster, during disaster, and post-disaster phases are represented (see Figure 1 for the components and stages of the DRM cycle).

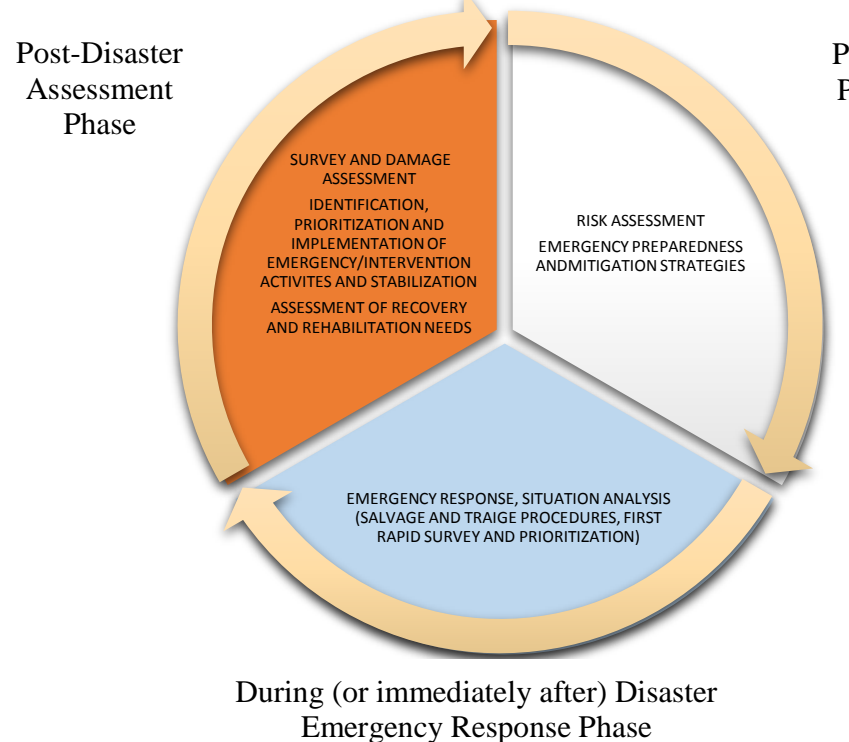

Pre-Disaster Preparation Phase
Figure 1. Cultural heritage disaster risk management (DRM) cycle and type of main activities/responses for each phase 
The system allows the following main types of information to be recorded and assessed:

1. Condition (level of damage) of the heritage place

2. Level of risk and vulnerability

3. Significance and value of the heritage place

4. Prioritization of heritage and activities and assessment of recovery needs (as well as identification of required interventions and responses)

The new entry fields have been developed for each of these elements (these elements are briefly introduced in the following sub-sections). For each data field, drop down lists of controlled vocabulary are developed to standardize data entry ${ }^{4}$.

In the updated version of the EAMENA database, heritage recording could be done at three levels:

1) the Heritage Resource Site where groups of sites and features could be recorded. At this level only main threats and disturbances will be identified and a relevant level of condition will be recorded (this level is mainly relevant for remote recording and assessment of heritage places).

2) the Heritage Resource Feature, where individual sites, monuments, buildings, etc, will be recorded separately. At this level risk and damage will be assessed

3) the Heritage Recourse Component level, where the assessment of individual components (e.g. column, wall, etc.) of the Heritage Resource could be carried out to record exact location and level of the damage to different components of a site or monument.

3.2.1 Damage Assessment: Ideally the initial phase of damage assessment involves the collection of all existing documentation and information, including old images, previous reports, assessment records, archived documents, etc. (though this may not be applicable in emergency recording where time is limited). The second step is a rapid field survey during which the actual state and condition of heritage places are assessed based on visual inspection (main focus of Syria HER). In a final stage, which may not occur in rapid assessments, an in-depth assessment can be conducted, ideally using an interdisciplinary approach with knowledgeable experts from relevant fields, to identify causes of damage and assess the severity and rate of deterioration (Demas, 2002; Paolini et al., 2012).

In conducting a rapid assessment, the surveyor needs to first identify and (1) locate the damage and (2) identify the damage (i.e. actual visible effect of disturbances). If possible (3) the cause of damage/disturbance could be recorded. Then the surveyor needs to assess the (4) extent and the (5) severity of the problem. The severity represents the strength and seriousness of the damage. The extent of damage represents the fraction of the assessed area affected by the disturbance. It is also important to differentiate between new and stabilized (and old) degradations by defining the (6) stability and trend of the damage. (7) The level of damage is calculated based on the level of extent and severity. In the end any (8) additional description and remarks and (9) photos could be added.

\footnotetext{
4 Harpring defines controlled vocabulary as "an information tool that contains standardized words and phrases to refer to ideas, physical characteristics, people, places, events, subject matter, and many other concepts. Controlled vocabularies allow for the categorization, indexing, and retrieval of information" (Harpring, 2010:1)
}

It should be noted that the data fields for damage assessment (identified above) and the fields for risk assessment (identified below) are developed to carry out a more detailed rapid assessment that follows the emergency assessment. In the emergency assessment only a subset of these fields will be used to 1) record main damage, 2) record what more damage can happen as a result (i.e. main threats), 3) record/add pictures and drawings, 4) identify the main priorities and implement emergency measures and immediate responses based on the initial emergency assessment to secure and safeguard the impacted heritage.

3.2.2 Risk Assessment: A condition assessment records existing damage and disturbances and provides information about the actual estate of the heritage place. A risk assessment on the other hand identifies and forecasts possible future damage and potential agents of deterioration (i.e. threats) (Taylor, 2005). As defined by Ball and Watt (2001), risk assessment is aimed at identifying threats and assessing the probability of their impact. Once threats are identified, the risk level can be assessed based on the likelihood (probability) and the severity of the identified threat interacting with the pre-existing vulnerabilities and exposure of a heritage place.

In the Syria HER after identifying the related vulnerability factors increasing the risk impacts for each heritage place, the surveyor identifies the threats and potential impact (part of the risk identification step in the figure 2 below). For each identified threat the level of impact needs to be estimated (risk assessment step in the figure 2). At this stage of the project, the level (magnitude) will be calculated as a product of probability $x$ extent $\mathrm{x}$ severity (where probability is defined as likelihood of risk occurring; extent is a total amount of assessed place to be affected by risk; and severity is defined as a product of the fraction of the assessed area susceptible to the threat and the potential loss in value of the area (Waller, 1995) $)^{5}$.

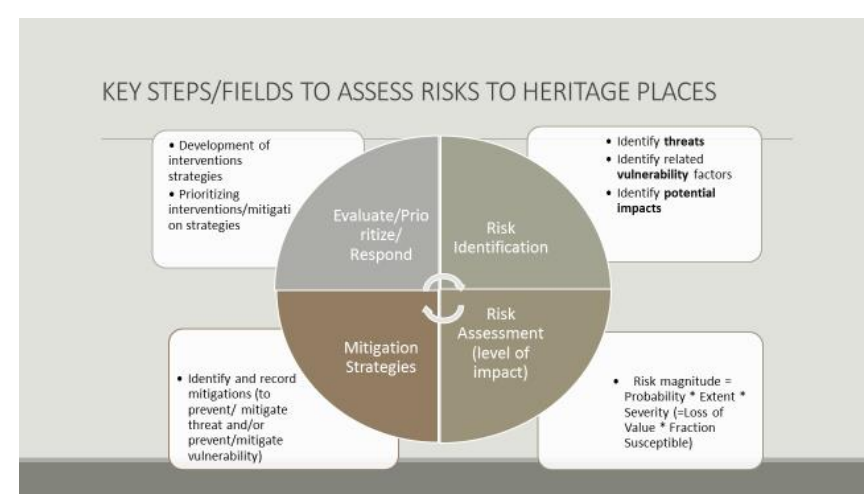

Figure 2. Risk assessment cycle 
3.2.3 Significance and Value Factors: In the rehabilitation and restoration phase (phase three in the DRM cycle), the question of value will influence heavily the conservation decisions and response. Identifying and assessing values and significance assists in the prioritization of heritage places and conservation and intervention activities. When decisions need to be made at a regional or country level in a post-disaster context, for example on where to start the rehabilitation work, and choices need to be made between different possible actions (from reconstruction, restoration or not touched), a holistic and clear method of assessment is needed. Should the decisions and prioritization be solely based on the degree of damage, the degree of rarity of a place, or the importance of destroyed and damaged sites and monuments for recovering tourism and the economy of the country? Or should they be based on the importance of the place for a population's identity and memory; the importance of the place in the post-war healing process and rebuilding of the cultural memory? Assessing values is neither an easy nor rapid task; the process is challenging and debatable. It needs a holistic approach in order to include all the above questions in the calculation. People and communities with varied beliefs and ideas, define and assign values differently. Values should capture the various components and interpretations of heritage and should include the sometimes conflicting (and changing) values identified by different stakeholders (and their conflicting interests). The process needs to be clear and transparent. For the maximum effectiveness of the Syria HER, identifying the most damaged and at-risk sites by itself is not sufficient to prioritize them for protection and conservation activities. In order to go to the next (admittedly challenging) level, components and categories of values need to be developed and a weighting system needs to be adopted on how to rank values assigned to a cultural heritage place (Isakhan, 2014; McManamon et al., 2016).

Traditionally in value-based approaches to conservation ${ }^{6}$, different lists of heritage values have been developed (i.e. value typologies) to assess heritage values and significance. In order to allow for more transparent and detailed evaluation of heritage values and assessment of potential conservation impacts on authenticity of heritage places, the Raymond Lemaire International Center for Conservation has developed a grid system called the Nara Grid. Based on the Nara Document on Authenticity, the Nara Grid introduces aspects of the sources (i.e. different layers or perspectives of a cultural heritage place) for each type or dimension of heritage value (artistic, historic, social, and scientific). Aspects of the sources defined in Nara Grid are: form and design, materials and substance, use and function, tradition, techniques and workmanship, location and setting, spirit and feeling. In this way values can be assigned and assessed for different perspectives (or aspects) of cultural heritage. And accordingly the impact of each intervention activity on any of the assigned values and layers can be understood and compared (Van Balen, 2008).

Similarly, Fredheim and Khalaf (2016) suggest a transparent, explicit, and holistic way of understanding and assessing significance by deconstructing the assessment into three stages of 1) what is the heritage or what they call features of significance to identify the features (layers) of significance, 2) why the heritage is valuable or aspects of value to identify why

${ }^{6}$ Values and value-based approaches to conservation have been at the core of site conservation and management plans and preservation each feature is significant (value typologies) and 3) how valuable the heritage is or qualifiers of value to assess the degree of significance (includes rarity, authenticity, condition, etc.).

By comparing these new studies, and examples of more explicit and holistic practices in significance assessment and value evaluation, the aim is to choose an appropriate method to identify the layers and categories of value and rank the level of significance. This work is ongoing.

\subsubsection{Priorities and identification of} Intervention/Mitigation Responses: As a result of the methodological approaches described above, heritage places will be prioritized based on the significance of the assessed area, the extent of damage and overall condition, and the risk magnitude. The higher the damage (and /or risk) and the higher the value of the heritage place, the higher the priority should be. Such a system when properly implemented will eventually produce a list of sites and monuments of significant importance which are considered to be in urgent need (i.e. prioritization list).

A possible list of interventions and mitigation measures has been developed for the project. Based on the identified damage and threat, and their level, emergency and intervention actions are identified. These responses and actions could be recorded during different phases of assessment: 1) emergency response and strategies and 2) rapid assessment response and identification of intervention activities.

The actions classified as intervention activities would record those conservation, preservation and management actions suggested to correct and treat the damage (in case of identified damage) or mitigate the threats (in case of identified threats and risks) that have been identified as part of the condition and risk assessment process. The identified intervention actions and activities are intended to protect and preserve the integrity of heritage places and mitigate any identified risks. A fixed and controlled vocabulary has been developed for the actions. In choosing activities, criteria such as intervention complexity and its feasibility given the available resources and local staff capacity would need to be considered.

While prioritization on the basis of the above would already be an important achievement, the prioritization abilities of the system could potentially go even further if the identified intervention activities and actions were also prioritized (again based on extent and severity of damage, the level of risk, significance of the assessed area, the overall impact of each different activity on the totality of identified values and features of the heritage). In this way all the identified management, conservation, and intervention activities could be listed based on their level of priority and the system could combine prioritization of needs and responses.

\subsection{Types of Analysis: Quantitative vs Qualitative}

The assessments and analysis explained in the previous subsections can be done based on qualitative or quantitative approaches and factors. In the qualitative approach words are used to describe and measure the elements of the assessment (e.g. level of severity and extent of damage). The quantitative approach uses numerical values to do the same. The decision between choosing the quantitative or qualitative approach is based on the degree of the detail of analysis sought, its purpose,

practices and principles (Sullivan, 1997; Demas, 2002; Mason and Avrami, 2000). 
and the information and resources available. The quantitative approach is more complicated and its development requires more time, resources, and research. Given the impact that the quantitative approach can have on subsequent data analysis, a quantitative system needs to be based on a higher level of expertise and scientific data (Australian and New Zealand Standards, 2004: 18-19).

At this stage of our project, a qualitative approach using ordinal measuring scales (i.e. rankings such as High, Med, and Low) is planned and used for measurement and analysis. These scale levels are defined and described in order to ensure users have a similar understanding of the terms. In order to produce an even more accurate system and facilitate the use of the system for prioritization decisions, it is envisaged that at a later stage a numerical weighting will be developed for each assessment field and level.

\section{CONCLUSION AND NEXT STEPS}

In order to effectively manage sites and monuments, a method is needed to rapidly assess the level of damage, threat and vulnerability and to set the heritage place's conservation priorities (at the site, local, and national level). In times of disaster and post-disaster if a country does not have baseline documentation of cultural heritage places it is unable to set strategies and priorities for post-disaster response. This can leave sites open to rapid removal by developers and/or land owners. The absence of documentation and prioritization systems also complicates the potential post-disaster support of donors and international heritage professionals.

In Syria, sites are being damaged, destroyed and looted. In the eventual post-war environment, major decisions will need to be made on where to start, how to implement the recovery phase and plan emergency measures, and how to allocate resources. Tools and methods need to be in place to quickly meet postconflict challenges.

The aim of this research at this stage is to develop a methodology embedded in an inventory database to give the national authorities and national and international heritage experts a powerful tool to document, assess, and identify the sites and monument that are in most danger and in need of rehabilitation. Such a database will also facilitate better prioritization by local authorities in their protection, conservation and restoration activities.

\subsection{Next Steps}

The next steps will involve both practical and technical steps to complete the work and further research on methodological issues.

The principle next steps to complete this research and work are to:

- Update and finalize EAMENA's graph structure with the new capabilities

- Start initial testing of the graphs

- Share with select colleagues and experts for peer review and collect their comments and recommendations

- $\quad$ Test in the field (Lebanon)

- Update the system based on field test and received feedback
Questions emerging from the work to date that require more research:

- What is the best way to quantify assessments of damage, risk and value? How can a suitable and effective numerical weighting system be developed to make comparisons and prioritization as between heritage places more meaningful?

- How should the potentially controversial issue of value assessment and significance be handled within a prioritization tool?

- Identifying and studying the reference case studies and examples of post conflict recovery in the past century (e.g. Balkan countries, Lebanon, etc.) What lessons can be learnt from how these countries have previously dealt with post disaster recovery, restoration and reconstruction? How can new technologies such as a GIS and digital databases, better address identified issues of past experiences?

\section{REFERENCES}

Ball, D. and Watt, J., 2001. Risk Management and Cultural Presentation. Proceedings of the ARIADNE Workshop 4, Vulnerability of cultural heritage to hazards and prevention measures, Prague (18-24 August 2001).

Bewley R.H. et al. 2016. Endangered Archaeology in the Middle East and North Africa: Introducing the EAMENA project. Campana, S. and Scopigno, R. (eds.), Proceedings of the 43rd Annual Conference on Computer Applications and Quantitative methods, Archeopress Archaeology, London, pp. 919-932.

Council of Europe, 2005. Guidance on Heritage Assessment our cultural diversity is what unites us. Strasbourg, Council of Europe.

Council of Europe, 2009. Guidance on Inventory and Documentation of the Cultural Heritage. Strasbourg, Council of Europe.

Council of Europe, 2012. "Guidelines on Cultural Heritage Technical Tools for Heritage Conservation and Management" Strasbourg, https://www.coe.int/t/dg4/cultureheritage/cooperation/Kosovo/ Publications/Guidelines-ENG.pdf

Demas, M., 2002. Planning for conservation and management of archaeological sites: a values-based approach. Teutonico, J. M. and Palumbo, G. (eds.), Management Planning for Archaeological Sites. Los Angeles, EEUU, Getty Conservation Institute.

FISH Inscription Standards, 2004 "REP93 Condition Word list" http://archive-info.com/page/776360/2012-1128/http://www.fish-forum.info/i_c_e.htm

Fredheim, L. H. and Khalaf, M., 2016. The significance of values: heritage value typologies re-examined. International Journal of Heritage Studies, 22(6), pp. 466-481. 
Getty Conservation Institute and World Monuments Fund, 2010. Middle Eastern Geodatabase for Antiquities (MEGA) - Jordan: Guidelines for Completing Site Cards, unpublished.

Getty Conservation Institute and World Monument Fund, 2016 "Arches Fact Sheets" http://archesproject.org/wpcontent/uploads/2016/08/Arches_factsheet_July_2016.pdf

Harpring, P., 2010. Introduction to Controlled Vocabularies: Terminology for Art, Architecture, and Other Cultural Works. Los Angeles, Getty Research Institute.

International Centre for the Study of the Preservation and Restoration of Cultural Property (ICCROM), 2005. "First Aid to Cultural Heritage in Times of Crisis" ICCROM. http://www.iccrom.org/wp-content/uploads/FAC2015-CourseInformation-2.pdf

ICOM / CIDOC Documentation Standards Group and CIDOC CRM Special Interest Group, 2015. "Definition of the CIDOC Conceptual Reference Model. Version 6.2.2" http://www.cidoccrm.org/docs/cidoc_crm_version_6.2.2\%20(WorkingDoc).pdf

International Council on Monument and Sites (ICOMOS), 1996. "Principles for the Recording of Monuments, Groups of Buildings and Sites" http://www.icomos.org/charters/archivese.pdf

International Council on Monument and Sites (ICOMOS), 2013. "The Australia ICOMOS Charter for the Places of Cultural Significance, The Burra Charter" http://australia.icomos.org/wp-content/uploads/The-BurraCharter-2013-Adopted-31.10.2013.pdf

Isakhan, B., 2014. Creating the Iraq Cultural Property Destruction Database: Calculating a Heritage Destruction Index. International Journal of Heritage Studies, 1, pp. 1-21.

Mason R. and Avrami E. 2000., Heritage values and challenges of conservation planning. Management Planning for Archaeological Sites, an International Workshop organized by the Getty Conservation Institute and the Loyola Marymount University May 2000, Corinth, Greece, pp. 13-26.

McManamon, F. P., Doershuk, J., Lipe, W. D., McCulloch, T., Polglase, C., Schlanger, S., Sebastian, L., Sullivan, L., 2016. Values-based Management of Archaeological Resources at a Landscape Scale. Advances in Archaeological Practice, 4(2), pp. 132-148.

Myers, M., Dalgity, A. \& Avramides, Y. 2016. Arches: A Free Software Platform Purpose-Built for Cultural Resource Inventories. The Alliance Review, National Alliance of Preservation Commissions, Summer 2016, pp. 22-27.

Paolini A., Vafadari, A., Cesaro G., Santana Quintero M., Van Balen K., Vileikis O., and Fakhoury L., 2012. Risk Management at Heritage Sites: a Case Study of the Petra World Heritage Site. Amman, UNESCO publication.

Standards Australia and Standards New Zealand, 2004. Risk Management: Companion to AS/NZ 4360:2004. Sydney, New Zealand.
Sullivan, S., 1997. A Planning Model for the Management of Archaeological Sites. In: M. de la Torre (ed): The Conservation of Archaeological Sites in the Mediterranean Region, an international conference organised by the Getty Conservation Institute and J. Paul Getty Museum, May 1995, Los Angeles, Getty Conservation Institute, pp. 15-26.

Taylor, J., 2005. An integrated approach to risk assessment and condition surveys. Journal of the American Institute for Conservation, 44(2), pp. 127-41.

The National Center for Preservation Technology and Training, 2011. "Rapid Building and Site Condition Assessment (updated)" $\quad$ https://www.ncptt.nps.gov/wpcontent/uploads/Rapid-NCPTT-Building-Site-AssessmentForm-2011-Update1.pdf

Vafadari, A., 2015. Guidelines for Conducting Rapid Condition assessment of Bagan Monuments, UNESCO Unpublished Report

Van Balen, K., 2008. The Nara grid: an evaluation scheme based on the Nara Document on Authenticity. APT Bulletin: Journal of Preservation and Technology, 39(2/3), pp. 39-45.

Waller, R. R., 1995. Risk management applied to preventive conservation. In: Rose, C. L., Hawks, C.A. and Genoways, H. H. (eds), Storage of Natural History Collections: A Preventive Conservation Approach, New York, Society for the Preservation of Natural History Collections, 21(8).

Waller, R. R., 2003. Cultural Property Risk Analysis Model: Development and Application to Preventive Conservation at the Canadian Museum of Nature. Ottawa, Canadian Conservation Institute.

Walton, T., 2003. Methods for Monitoring the Condition of Historic Places. Wellington, New Zealand Department of Conservation. 